\title{
GENDER BELIEFS AND FAMILY RESPONSIBILITIES AS PREDICTORS OF CONFLICT AND ENRICHMENT IN PARENTS OF CHILDREN WITH DISABILITIES
}

\author{
MONIKA PARCHOMIUK \\ Institute of Pedagogy, Faculty of Pedagogy and Psychology, University of Maria Curie Sklodowska, Głęboka Street 45, \\ 20-612 Lublin, Poland, contact: mparchomiuk@o2.pl
}

Received: 14.04.2021.

Accepted: 11.10.2021.

Original research article

UDK: 159.922-055.5/.7:37-053.2-056.26/.34

doi: 10.31299/hrri.57.2.1

\begin{abstract}
This study examined the contribution of parental beliefs, the scope of involvement in family responsibilities, and the sense of being burdened with these responsibilities in shaping the results of conflict and enrichment in the roles of parents of children with disabilities, while keeping the child's functional status in mind. We analysed data from 168 respondents, including 99 mothers and 69 fathers of children with disabilities. Beliefs, sense of burden with household and family responsibilities, and the child's functional status had an influence on family-work conflict. The parent's gender, beliefs, the child's functional status, sense of burden with responsibilities towards the child with a disability, and the scope of involvement in household and family responsibilities were important for enrichment.
\end{abstract}

Keywords: children with disabilities; gender role beliefs; parental roles; responsibilities; work-family conflict; work-family enrichment

\section{INTRODUCTION}

Over the last several decades, two trends have been observed in the roles and tasks undertaken by women and men (Boyd, Iacono \& McDonald, 2019; Öun, 2012): more women have entered the labour market and more men have taken up family responsibilities. However, many authors point out that, in addition to being professionally active, women perform the larger proportion of family responsibilities, including those related to the household and childcare (Fernandez-Cornejo et al., 2016; Mencarini \& Vignoli, 2018). These general trends vary depending on specific socio-cultural, legal, and economic conditions, which are, on the one hand, the source of these trends, and on the other hand, determine the course of the trends. Such conditions include, among others, the system of beliefs and values, expectations regarding gender roles, the scope of informal and formal support, and organisational policies in the workplace (Beham et al., 2020; Biçaksiz, 2009; Cooper et al., 2019; Jaga \& Bagraim, 2017; Öun, 2012; Rajadhyaksha, Korabik \& Aycan, 2014; Steiber, 2009). Parents perform their roles within a specific socio-cultural context that provides a standard for how such roles should be performed, as well as evaluates this performance (Favez et al., 2016).

Literature on the subject uses different terms to describe the phenomenon in which an individual divides their time between paid work and family responsibilities, while making sure to take gender into account, including gender ideology, gender role attitudes, attitudes about gender, gender-related attitudes, or even gender egalitarianism (Davies \& Greenstein, 2009). In this study, we adopted the term "gender role beliefs" assuming that they constitute a cognitive schema combined with the sense of parental competencies, in combination with other variables that define specific parental behaviours in the family and at work (Favez et al., 2016). These beliefs are not the same as attitudes towards gender since they do not include a behavioural component. 
Furthermore, they also differ from gender-related behaviour (Claffey \& Mickelson, 2009; Gaunt, 2006). Based on the empirical dimension of beliefs, we assumed that gender role beliefs comprise of a bipolar continuum with an egalitarian (non-traditional) and a traditional end (Somech \& Drach-Zahavy, 2007; Steiner, Krings \& Wiese, 2019). Such beliefs have their source in factors of primary and secondary socialisation, as well as individual experiences (Fortin, 2005; Kaufman \& White, 2016; Kroska \& Elman, 2009; Walls, Helms \& Grzywacz, 2016).

Empirical data suggests that gender role beliefs include both beliefs describing the responsibilities of women and men, as well as the evaluation of the roles and tasks assigned to them from the perspective of family members, especially children (Gaunt, 2006; Kaufman \&White, 2016; Steiner et al., 2019). Traditional beliefs assume that there is a strict division of gender roles. The woman has to take up family responsibilities, including the care and upbringing of dependent family members, which is justified by her predispositions and most beneficial for the entire family. It is believed that if the woman is employed, it can have a detrimental effect on her children's development and limit the resources that she can invest in her family roles. Traditional beliefs explain the role of the man as supporting the family through work, but not engaging in family responsibilities. Egalitarian beliefs broaden the spectrum of roles for both sexes, assuming the possibility or even benefits of mothers taking up professional work and fathers engaging in family life (Gaunt, 2006; Kaufman $\&$ White, 2016; Steiner et al., 2019). The traditional belief system includes stereotypical models of "a good mother" and "a good father". A "good mother" is a woman who devotes herself to the family by expressing her constant readiness and availability to meet familial needs while neglecting her own needs (Kaufman \& White, 2016; Lewis, 2000, in Leiter et al., 2004; Steiner et al., 2019). The stereotype of a "good mother" accumulates several beliefs that have been captured in Hays's intensive mothering ideology (1996, in Walls et al., 2016, p. 2), which states that "children are innately good or innocent, mothers should be self-sacrificing and primary caregivers, and correct childrear- ing requires all of the mothers' time, energy, and resources". Work potentially limits this readiness and availability (Duxbury \& Higgins, 1991).

In public opinion, motherhood seems to be the prototype of parenthood, accumulating all its important features against which the quality of good fatherhood is assessed (Perälä-Littunen, 2007). A "good father" is a professionally successful breadwinner who is not expected to be directly responsible for childcare (Chou, Kroger \& $\mathrm{Pu}$, 2016). Modern working mothers have developed a new ideology of good motherhood, comprising an element of providing the child with economic security and high-quality care, while sharing responsibilities with their partner (Walls et al., 2016). This can presumably be considered an element of the modern woman's adaptation to the reality where egalitarian trends are more prevalent. This is especially true for women living in countries offering solutions facilitating these trends (Öun, 2012; Steiber, 2009). There are no in-depth analysis devoted to parental beliefs in the population of mothers and fathers raising a child with a disability. The stereotype of "an irreplaceable mother devoting herself to the child's welfare", which is characteristic of the traditional belief system, is particularly applicable to mothers raising a child with a disability, since they are expected by the social environment to give up other roles and fully focus on their child's needs (Sheran \& Todd, 2000). This may make them feel guilty and anxious, and even depressive when they start working and share sharing responsibilities with others (Sheran \& Todd, 2000; Sitimin et al., 2017; Taylor, 2005 et al.).

Numerous studies on beliefs have shown how beliefs operate in women and men in the context of realised and planned family and professional lives (Jugović, 2015; Perry-Jenkins et al., 2017). Longitudinal studies showing trends in sharing the labour market, starting a family, making decision on procreating, and being satisfied with marital life are particularly useful in this regard. They show that women's egalitarian attitudes and participation of men in family life are associated with greater involvement of women in the labour market, including both taking up employment and longer working hours (Cunningham, 2008; Fortin, 2005; Harris \& Fireston, 1998). 
Caring for a child is a complex construct involving many tasks, making it highly time consuming and energy-draining (Badawy \& Schieman, 2019). Childcare and household chores that fulfil the needs of family members, referred to as "invisible work", require committing significant engagement and resources, including time, but do not necessarily bring spectacular and appreciated effects (Kaplan, Sabbah-Karkabi \& Herzog, 2020). Studies show that a mother's experience of caring for her child is much more beneficial than her experience of doing routine household chores. This affects the mother's level of satisfaction and sense of burden when performing both types of duties (Kaplan et al., 2020).

In the event of a disability or illness of a family member, the scope of tasks is extended to tasks related to therapy and rehabilitation. Parents of children with disabilities undertake additional tasks resulting from their participation in therapy, education, and care, as well as defending their child's interests, searching for optimal ways to support their child's development, sharing experiences within parent groups or conferences, broadening their knowledge about disability, and acting as members of advisory groups in various institutions and organisations. These tasks consume time and energy, but they may also be a source of new personality traits and social competencies, or could lead to strengthening existing ones (Churchill et al., 2010; Ryan \& Runswick-Cole, 2008; Schippers et al., 2020).

Research shows that taking up family responsibilities (including childcare and household chores) is often the father's decision, but it is something that is obvious for women starting a family, whether they work professionally or not (Duxbury \& Higgins, 1991; Perälä-Littunen, 2018). It is predominantly women who fulfil domestic and parenting responsibilities, even if they are professionally active like the fathers (Fernandes-Cornejo et al., 2016; Haines et al., 2019; Kaplan et al., 2020). Bearing in mind future family and professional roles, women are more likely to assume that they will need to and are ready to limit building their professional career because of family responsibilities (Fernandes-Cornejo et al., 2016). Factors that may be important for taking up family roles and the degree of involvement in their implementation include, among others, specific beliefs, including the ones regarding the mother's competencies, the essence of parenthood, and gender role beliefs (Cooper et al., 2019; Hergatt Huffman et al., 2014; Kuo, Volling \& Gonzalez, 2018).

The following trends in the area of gender role beliefs were found to be of interest for the present research study:

1. Beliefs differentiate the global scope of parental involvement or commitment to specific tasks. Gender roles and beliefs may affect the way these tasks are assessed and prioritised. Kuo et al. (2018) mentioned that fathers presumably view love and support for their child and accompanying him/her in play and other activities as important aspects of fatherhood. From their perspective, engaging in everyday practical tasks (such as grooming) may be less important. Therefore, the mother's attitudes and beliefs are an important factor determining the father's participation in childcare (Meteyer \& Perry-Jenkins, 2010; Zvara, Schoppe-Sullivan \& Kamp Dush, 2013).

2. Egalitarian fathers are more likely to support mothers in household chores by appreciating the importance of their professional work for personal and family life. Research also shows that egalitarian attitudes of men (but not women) have a positive impact on their involvement in childcare and psychosocial adaptation (Riina \& Feinberg, 2012). Observing social changes over several decades, Nomaguchi (2009) also pointed out the importance of social pressure that forces fathers to share household duties with their working wives: such pressure is often greater for fathers who hold traditional views. Mencarni and Vignoli (2017) showed that fathers with traditional attitudes towards gender roles are less likely to take up household duties and are more likely to be dissatisfied with their wives' employment. The relationship between traditional beliefs and low amounts of time spent by men doing housework and caring for dependent family members was also confirmed by Huffman et al. (2014).

3. Parents with egalitarian attitudes may more often share certain caring tasks with others, 
including institutions. As mentioned before, modern mothers may construct a new ideal of a good mother, adjusted to the reality where they undertake professional work for various reasons. A priority, but also an element of this ideal, is to provide the child with high-quality care (Walls et al., 2016).

Research also shows that a father's involvement in caring for a child with a disability is related to the father's professional work and working hours, the mother's professional work and her working hours, the child's age, and the type and degree of the child's disability (Chou et al., 2016; MacDonald \& Hastings, 2010; Potter, 2017). The trend showing greater involvement of fathers in family responsibilities when mothers are professionally active is consistent with the one observed in families with non-disabled children (Feinberg, 2003; Webber \& Williams, 2008). When raising a child with a disability, the traditional beliefs of mothers regarding work and motherhood were found to be insignificant (Chou et al., 2016) when considered in contrast to a father's belief about their important role in childcare (Mavrogianni \& Lampropoulou, 2020). A mother's belief about their irreplaceable role in childcare can affect the nature of a father's involvement, similar to that observed in families in the general population (Olrick, Pianta \& Marvin, 2002). Other studies including both parents have shown that greater involvement in caring for a child with a disability is associated with a lack of initiative to start working and dissatisfaction with the partner's caregiving abilities (Ozgun \& Sterling Honig, 2005).

Simultaneous involvement in family and professional roles, motivated by many reasons, may trigger positive and negative phenomena, such as conflict and enrichment (enhancement). Enrichment is the extent to which experiences in one role increase the quality of life in another role, and it is indicated by the level of activity and positive feelings or mood (Greenhaus \& Powell, 2006). Physical, mental, social, and organisational resources are key for gaining experience in one's roles. In the domain where they are acquired and developed, these resources facilitate performing tasks associated with the role, they help reduce burdens, and generate additional resources (Voydanoff, 2004; 2005).
They can be transferred directly (instrumental path) and indirectly (affective path) in other domains, and may become useful in dealing with the requirements related to additional role(s) (Carlson et al., 2006). Indicators of enrichment in the instrumental path include conflict resolution skills and the development of certain predispositions. Enrichment in the affective path strengthens positive emotions and mood, which can improve role performance (Carlson et al., 2006). Strong enrichment reflects the degree to which an individual is enthusiastic, energetic, exhibits improved concentration and a good mood (Wayne et al., 2007). Enrichment is multidimensional and may occur with varying intensity in both directions: work-family and family-work (Carlson et al., 2006).

Work-family conflict is "a form of inter-role conflict in which the pressures from work and family domains are mutually incompatible in some respect. That is, participation in the work (family) role is made more difficult by virtue of participation in the family (work) role" (Greenhaus \& Beutell, 1985 , p. 77). Conflict is caused by difficult or impossible requirements such as structural or psychological expectations arising from organisational and normative aspects of the role that the individual must respond to (which requires adaptation) by making a physical or mental effort (Voydanoff, 2005). Greenhaus and Beutell (1985) distinguished two types of role conflict: (a) behavioural conflict indicating that behaviours shaped in one role (even expected of it) are harmful, unnecessary, and disruptive to the other role, (b) conflict occurring over time, and (c) tension (including mood and energy). Conflict, like enrichment, is bidirectional: work-family and family-work, and empirical evidence indicates that these constructs are relatively independent of each other (Grzywacz et al., 2008). Work-family conflict means that the factors responsible for its occurrence come from the work environment. The family-work conflict means that they come from a family background.

Mothers of children with disabilities are less likely to take up or return to work than fathers and mothers of non-disabled children (Brennan, Brannan, 2005; Crettenden, Wright, Skinner, 2014; Einam \& Cuskelly, 2002; Hauge et al., 2013). Compared to fathers, mothers are more likely to 
give up their professional life to take care of and educate the child (Ozgun \& Sterling Honig, 2005). Empirical data also shows specific trends in fathers, who may find extra work or work longer hours to cover increased expenses, and who also report career limitations and difficulties in reconciling work with raising a child (Pancsofar et al., 2020; Schippers et al., al., 2020; Wright, Crettenden \& Skinner, 2016). Many factors affect the trends described here, including the stability of the child's health, the degree of the disorders, and the associated requirements for care and nursing (Brennan \& Brannan, 2005; Leiter et al., 2004; Rupp \& Ressler, 2009), as well as access to informal and formal support based on the needs of the family (Brown, 2014; Crettenden et al., 2014; Schippers et al., 2020). Research also indicates positive outcomes when mothers and fathers of children with disabilities take up professional roles, such as the development of resources (e.g., support networks), coping abilities, positive self-image traits, energy, and meeting psychosocial needs. All the above are used in family life, including when providing care for and bringing up a child with a disability (Einam \& Cuskelly, 2002; Pancsofar et al., 2020; Sheran \& Todd, 2000), which may indicate enrichment. This construct, similar to role conflict, is almost unrecognised in the population of parents of children with disabilities. Previous studies, including those with parents of children with a disability, have explored contextual factors of enrichment and negative phenomena (such as interference and family-work conflict) in the personal sphere and the environment (Brown, 2014; Brown \& Sumner, 2019). However, the largest sample in these studies were mothers, and the regression models tested both phenomena separately.

There is disagreement about the trends in the direction of conflict and enrichment in women and men. Some studies provide evidence that for women, family has a stronger influence on work, while for men, work has an effect on family life (Aryee, Srinivas \& Tan, 2005; Voydanoff, as cited in Brummelhuis et al., 2008; Simon, as cited in Gray, 2003). Examining the extent of this trend, depending on the nature of beliefs, can help us understand how they will be significant for work-family and family-work conflict and enrichment.
Studies conducted so far, mainly in groups of parents raising non-disabled children, suggest that the gender variable plays a distinguishing role for both phenomena. However, there is no uniformity in the trends related to how gender shapes conflict and enrichment. Some studies show higher conflict in women (DePasquale et al., 2017; Öun, 2012), while others show no significant gender differences (Haines et al., 2019; Smith, Yu \& Le, 2020). With respect to enrichment, some studies indicate a significantly higher enrichment in women (Beham et al., 2020; Van Steenbergen, 2007), while others show no differences (Jaga \& Bagraim, 2011), or different results depending on the direction of enrichment (Rothbard, 2001). Huffman et al. (2014) pointed out that, from the perspective of conflict analysis, it is useful to verify the influence of gender along with the influence of beliefs.

It has been suggested that socialisation is important to fulfil social roles and expectations directed at people of different sexes (McNall, Nichlin \& Masuda, 2010). Women and men create different beliefs about family and professional roles, and their activity in these areas (depending on many personal and environmental factors) provides them with experiences consistent or inconsistent with these beliefs. In addition, the roles they take on are associated with different social assessments and support systems, which also affects the possibility of their successful implementation (Young, 2019).

Previous studies have verified the relationship between conflict and the beliefs of women and their partners, as well as working women and men (Šimunić, Pandža \& Gregov, 2017; Steiner et al., 2019). Studies have also addressed the role of beliefs in moderating strategies for coping with conflict (Somech \& Drach-Zahavy, 2007). The significance of gender role beliefs is confirmed by qualitative analyses showing that women report greater conflict if their husband's hold traditional beliefs. The key factor here is the perception of inequality in the division of duties resulting from the fact that the partner has a smaller share (Jaga \& Bagraim, 2017). This trend has been confirmed by Šimunić et al. (2017), who showed that higher conflict in women and men is associated with stronger traditionalism of married men. Traditional fathers 
who spend less time on caring responsibilities experience less work-family conflict, although no such relationship has been demonstrated in relation to the family-work conflict. Fathers with traditional beliefs may not consider devoting more time to work as a burden, since their commitment to work allows them to confirm their beliefs, especially in terms of being "a good breadwinner" (Huffman et al., 2014). Steiner et al. (2019) found that higher work-family conflict occurs in mothers with more traditional beliefs and a higher workload. Although most research shows a trend indicating a positive relationship between conflict and traditional beliefs in both sexes, few studies show the opposite trend. Hatchman (2009) showed that non-traditional attitudes in working mothers are associated with higher work-family conflict. Likewise, there may be a positive relationship between conflict and egalitarian beliefs in men, although no evidence has been found to support it. Kaufman and Uhlenberg (2000) mentioned that when fathers express their need to participate in family life or when they actively participate in it (stronger egalitarian beliefs), including childcare, they can see work and family as competitive and find it difficult to reconcile the two domains. Nomaguchi (2009) found that egalitarian fathers, who recognise the need to spend more time with their child (social expectations about the role of the father) and are engaged in activities with the child, have less time overall, which may cause conflict. However, if fathers do not see the role as central (giving it meaning), then their egalitarian beliefs are associated with lower conflict (Gelb, 2014). Studies on gender and beliefs indicate a stronger relationship of ideology with family-work conflict in women: it has been noted that women with traditional views tend to experience stronger conflict (Bicaksiz, 2009).

The trends described above may be explained as follows:

(d) Conflict may occur due to a mismatch between a mother's traditional beliefs about gender roles and her job. Working women who hold such beliefs may think that investing in work limits family obligations expected of them, which are often assessed by the environment (and themselves) as the most important responsibilities in their lives (Steiner et al., 2019). In this case, work-family conflict may be expected. On the other hand, in the case of working women with egalitarian beliefs, the need for dominant (socially expected) participation in family responsibilities may provoke familywork conflict. Conflict can occur as a result of contradicting behaviour and beliefs (Gartrell Hatchman, 2009). As we mentioned earlier, modern working women, regardless of the nature of their beliefs, dominate men in terms of household duties.

(e) In the case of men with traditional beliefs, family-work conflict can occur when they assume that their professional role is more important, and they have to take up household duties by choice or out of necessity dictated by the fact that their wives are unavailable due to work (Kuo et al., 2018; Nomaguchi, 2009).

(f) Traditional beliefs in male partners may make them dissatisfied with their wife's employment and result in them not providing her with sufficient support in family responsibilities (Šimunić et al., 2017), consequently leading to an increase in conflict in the wife (work-family and family-work) because she is overburdened with duties.

Very few studies have investigated enrichment, but we can assume that egalitarian attitudes of working women will be more conducive to perceiving positive aspects of functioning in family and professional roles. A study involving European women showed that women's involvement in multiple roles is beneficial, especially in a favourable egalitarian social climate, as it increases the transfer of resources between work and family (Beham et al., 2020): this study also confirmed a significant trend indicating a negative relationship between traditional attitudes of European women and higher family-work enrichment. Egalitarianism can increase the moderating contribution of enrichment in the relationship with work-family balance in working parents (Bansal and Agarwal, 2019). With limited data on enrichment, we cannot establish the nature of its relationship with beliefs. Therefore, the present study aimed at examining the relationship between gender role beliefs and family responsibilities on conflict and enrichment in families with a child with a disability. 


\section{OBJECTIVES AND RESEARCH PROBLEMS}

The findings so far point to the complexity of the problem, but also provide several consistent trends about the importance of gender role beliefs for family and professional roles and specific experiences related to them. Individuals take up roles and tasks by choice or out of necessity (Kaufman \& White, 2016; Kuo et al., 2018). A woman with traditional views might choose to look for work due to a difficult economic situation in her family. On the other hand, engaging the father in caring for his child may be associated with a lack of formal (institutional) and informal (from other family members) support. Both parents may not want to choose institutional care for their child due to previous negative experiences that may suggest the poor quality of this support. Such decisions are made by parents of children with disabilities who often experience a more difficult economic situation, limited environmental resources, and unfavourable experiences of searching for and using additional family care for children with disabilities of different ages (Alborz, 2003; Davys \& Haigh, 2007; Warfield, 2005). In such situations, behaviour related to work and family does not have to be consistent with beliefs (Butler \& Skattebo, 2004; Kaufman \& White, 2016). However, this incompatibility exacerbates the experience of negative phenomena such as conflict and blocks the experience of the benefits of taking family and professional roles at the same time. Raising a child with a disability is related to several specific requirements that are not faced by parents of non-disabled children (Churchill et al., 2010; Feldman et al., 2007; Ryan \& Runswick -Cole, 2008; Schippers et al., 2020; Van Riper, 2007). Depending on the child's level of functioning, including his/her basic life competencies, the intensity of care and upbringing obligations may vary. On the other hand, their implementation takes place in the context of specific personal and environmental resources available to the parents, which affects their scope, quality, and sense of burden. In this case, the scope of duties or the sense of burden may also be important. In the case of men, it is not easy to infer the possible operation of beliefs in terms of both phenomena. It seems that participation in family responsibilities is of key importance, since it clashes with traditional beliefs, which may be a source of family-work conflict.

Until now, such research has been carried out mainly with parents of non-disabled children. No data is available for mothers and fathers who have children with various types of disabilities. Researchers focused primarily on negative phenomena, such as conflict in both directions, whereas enrichment was rarely considered. Both these phenomena are complementary to understanding the balance of functioning in the roles of working parents (Wayne et al., 2019).

In the present study, we examined the contribution of parental beliefs, the scope of responsibility borne in connection with family duties (related to a child with a disability, as well as home and family matters,) and the sense of burden in shaping the results of conflict and enrichment in the roles of parents (in both directions: family-work and work-family). We considered the gender of the parents, as well as the functional status of the child with a disability, which is an indicator of the child's ability to perform basic self-care activities and the child's mobility. We did not examine duties related to non-disabled children since not all families had non-disabled children.

\section{METHODS}

We recruited working parents who had a disabled child between the ages of 3 and 18 years. The child's disability was confirmed either by the Poviat Team, which is an institution that deals with disability certificates in Poland, after assessing the type and degree of disability, or by a psychological and pedagogical counselling centre. Parents were recruited through educational organisations across Poland, such as training and education centres, special care educational centres, and groups of schools consisting of kindergartens, various levels of schools, or boarding schools. First, online educational databases were analysed to identify institutions focused on a specific type of disability. A total of 40 institutions for children and adolescents with intellectual, motor, and sensory disabilities (including individuals with autistic spectrum disorders in selected centres) were identified from different regions. Sets of questionnaires along with 
detailed information on the purpose and the issues raised in this study, criteria for selecting the study subjects, confirmation of the author's affiliation to the university and their contact details, plus return envelopes were sent by post to the management offices of these centres. In all cases, an employee was appointed by the management to be responsible for handing over the questionnaires to parents (with their consent) and for collecting the questionnaires for posting once they had been filled out.

The study described here is part of a broader research project aimed at examining the predictors and consequences of conflict and enrichment in parents raising a child with a disability. The concept of the project was approved as a statutory study of the university. As part of the project, the topic, data collection, participant recruitment procedures, and eligibility criteria were approved. This selection method was used to ensure maximum group diversity in terms of certain variables characterising parents and children. Because parents were recruited through educational institutions and not associations, it avoided the specificity of the group in terms of certain features possessed by parents who are active in self-help activities. However, participation in the study was not associated with any gratification and required a voluntary decision, which could have affected the inclusion of people who, for example, had a stronger need or greater competence to share their own experiences.

We collected data from 242 parents who were bringing up a child with a disability aged 3 to 18 years. There were 121 married couples in this group: 121 mothers and 121 fathers. After rejecting questionnaires with incomplete information, we used data collected from 168 respondents (Mean $(M)$ $=43.08$ years, Standard deviation $(S D)=6.98$, Range $=30-61$ years), including 99 mothers and 69 fathers. All respondents were married and lived with their partner and children. All respondents were employed, with $40.42 \%$ working eight hours a day, $22.34 \%$ working less than eight hours a day, and $26.06 \%$ working more than eight hours a day. The length of employment of the respondents varied $(M=18.91$ years, $S D=8.09$, Range $=7-44$ years $)$. The respondents raised at least one child with a disability $(M=11.34$ years, $S D=3.91$, Range $=3-18$ years), and these disabilities included: intellectual disability (ID) (34.71\%), sensory disability (SeD) (22.31\%), physical disability (PD) (10.74\%), autism spectrum disorder (ASD) (10.74\%), and multiple disabilities (ID+PD/ID+SeD) (20.66\%). Most of the parents $(63.3 \%)$ had no problem providing care for their child with a disability. Forms of care included: educational institutions (49.28\%), grandparents $(39.67 \%)$, one of the parents $(26.45 \%)$, siblings $(9.92 \%)$, and others $(15.7 \%)$. The total number of children (with and without a disability) in each family ranged from 1 to $3(M=1.81, S D=0.78$, Range $=1-3)$. The age of the youngest child varied from 15 months to 18 years $(M=10.56$ years, $S D=4.11)$.

The Work-Family Conflict Scale by Matthews, Kath, and Barnes-Farrell consists of six statements on a 7-point scale (from "strongly disagree" to "strongly agree"). The role of conflict is diagnosed based on three aspects - time, tension, and behaviour (observed in both directions: family-work, work-family). In two validation studies conducted by the authors of the instrument, Cronbach's alpha indexes ranged from 0.75 to 0.8 for work-family conflict and from 0.71 to 0.72 for family-work conflict (Matthews, Kath \& Barnes-Farrell, 2010). In the present study involving parents of disabled children, Cronbach's alpha was 0.77 for work-family conflict) and 0.95 for family-work conflict.

The Work-Family Enrichment Scale by Carlson, Kacmar, Wayne, and Grzywacz was used to determine enrichment in family and professional roles in two directions: work-family and family-work, and in three dimensions: (a) development (strengthening of skills, knowledge, behaviours, and a change in perception of reality that helps a person be a better employee or family member); (b) affect (involvement in work /family causes positive emotional states and attitudes that help a person be a better employee/family member); (c) and capital (involvement in work/ family increases the level of psychosocial resources, such as the sense of security, trust, self-fulfilment, which helps to be a better employee or family member). The scale consists of 18 statements (nine for each direction) and respondents score the statements on a 5-point scale. Only the endpoints of the scale are defined ("I strongly disagree" - "I strongly agree"). Cronbach's alpha calculated by the authors of the scale ranged from 0.73 to 0.9 for work-family enrichment and from 0.82 to 0.91 for family-work enrich- 
ment (Carlson et al., 2006). Cronbach's alpha for the parents of children with disabilities in the present study was 0.85 for work-family enrichment and 0.77 for family-work enrichment.

The Gender Role Beliefs Scale is a scale that we developed on our own. Many scales in the literature examine gender beliefs and attitudes. Some date back to the 1970s-80s (Dodson \& Borders, 2006; Kuo, Vollling \& Gonzalez, 2018; Marks, Bun \& McHale, 2009), while others are more recent (Beham et al., 2020; Gelb, 2014). Previous studies have used selected items from ready-made scales, which does not seem to be a beneficial procedure (Zvara, Schoppe-Sullivan \& Kamp Dush, 2013). Considering the Polish thematic research resources, there was no scale that was developed in Poland or adapted to Polish socio-cultural conditions. This self-developed scale consists of six statements describing beliefs about the division of professional and family roles and tasks, as well as their significance from the perspective of the individual and the social environment (e.g., "It is more beneficial for each family member when the man supports the family financially and the woman takes care of the house and the family"). Responses ranged from 1 indicating "strongly disagree" to 4 indicating "strongly agree". Higher scores on the scale indicate stronger traditional beliefs. Reliability for this scale was 0.61 . This low Cronbach's alpha may be due to the relatively small pool of items in the scale. Nevertheless, it is accepted by researchers even though it lower than the conventionally accepted 0.7 (Perales, Jarallah \& Baxter, 2018; Taber, 2018).

\section{The Scale of The Division of Family} Responsibilities was also developed for the purpose of the present study and it consists of two subscales. The first is used to define the subjectively assessed scope of responsibility related to a given duty (on a scale from 0 - "it does not apply to my family situation" to 4 - "it always applies to me"). The second serves to verify the sense of burden felt while fulfilling the responsibility (on a scale from 1 - "light burden" to 4 - "very heavy burden"). Following the instructions, respondents assess the sense of burden with the duties they fulfil. The scale includes 12 responsibilities related to bringing up a child with a disability (e.g., nursing activities), and 11 related to taking care of a non-disabled child (similar to that of a child with a disability, excluding tasks related to rehabilitation), where two are related to taking care of other dependent persons in the family and nine to home and family life in general (e.g., shopping, organising free time for the family). Two of these responsibilities were used in the present analysis. Good reliability was observed for the scope of responsibilities undertaken towards a child with a disability $(\alpha=0.9)$, the sense of being burdened with responsibilities towards a child with a disability $(\alpha=0.91)$, the scope of household and family responsibilities undertaken $(\alpha=0.85)$, and the sense of being burdened with household and family responsibilities $(\alpha=0.93)$. The questionnaire designed for the present research study was also used to collect general information about work, family, and the child with a disability.

\section{RESULTS}

First, descriptive statistics were calculated for all analysed variables (Table 1). Second, we tested for correlations between all the variables (Table 1). The main statistical analyses focused on multiple linear regression models with conflict and enrichment as criteria, the parents' beliefs about gender roles and responsibilities as predictors, and the parent's gender and child's functional status as covariates. The results of these analyses are presented in Tables 2 and 3.

Initial analysis of the correlations between the criteria and the predictors showed few weakly significant relationships. Sex had no effect on conflict in either direction, but it had significant relationships with all aspects of work-family and family-work enrichment. Therefore, this variable was included in further analyses as a covariate of conflict and enrichment. The child's functional status, describing the child's level of independence and mobility, correlated significantly with affect in the work-family direction. Interestingly, this relationship was negative. the child's functional status was also included as a covariate in the model for testing the conflict and enrichment predictors. The other variables describing parents' beliefs regarding gender and taking up duties, apart from the sense of being burdened with duties related to the child with a disability, had significant relationships 
Monika Parchomiuk Monika Parchomiuk Monika Parchomiuk: Gender beliefs and family responsibilities as predictors of conflict and..

Table 1. Descriptive statistics and correlations (r-Pearson) among predictors and outcome variables

\begin{tabular}{|l|c|c|c|c|c|c|c|c|c|c|c|c|c|c|c|c|}
\hline Variable & M & SD & $\mathbf{1}$ & $\mathbf{2}$ & $\mathbf{3}$ & $\mathbf{4}$ & $\mathbf{5}$ & $\mathbf{6}$ & $\mathbf{7}$ & $\mathbf{8}$ & $\mathbf{9}$ & $\mathbf{1 0}$ & $\mathbf{1 1}$ & $\mathbf{1 2}$ & $\mathbf{1 3}$ & $\mathbf{1 4}$ \\
\hline FS (range: 6-18) & 15.69 & 3.23 & - & - & - & - & - & - & - & - & - & - & - & - & - & - \\
WFC (range: 3-21) & 10.88 & 10.42 & -0.11 & - & - & - & - & - & - & - & - & - & - & - & - & - \\
FWC (range: 3-21) & 8.68 & 3.49 & -0.11 & $0.39 *$ & - & - & - & - & - & - & - & - & - & - & - & - \\
WFE-D (range: 3-15) & 10.26 & 2.72 & -0.1 & -0.08 & -0.13 & - & - & - & - & - & - & - & - & - & - & - \\
WFE-A (range: 3-15) & 9.88 & 3.08 & $-0.18 *$ & $-0.23 *$ & -0.07 & $0.68 * *$ & - & - & - & - & - & - & - & - & - & - \\
WFE-C (range: 3-15) & 10.43 & 2.77 & -0.12 & $-0.18^{*}$ & -0.07 & $0.75^{* *}$ & $0.78^{* *}$ & - & - & - & - & - & - & - & - & - \\
FWE-D (range: 3-15) & 10.33 & 2.97 & -0.09 & -0.15 & $-0.18^{*}$ & $0.75^{* *}$ & $0.65^{* *}$ & $0.72 * *$ & - & - & - & - & - & - & - & - \\
FWE-A (range: 3-15) & 10.78 & 3.01 & -0.07 & -0.15 & $-0.17 *$ & $0.75^{* *}$ & $0.70^{* *}$ & $0.70^{* *}$ & $0.73^{* *}$ & - & - & - & - & - & - & - \\
FWE-C (range: 3-15) & 10.54 & 2.77 & -0.00 & -0.13 & $-0.21 *$ & $0.71 * *$ & $0.59 * *$ & $0.67 * *$ & $0.83^{* *}$ & $0.72 * *$ & - & - & - & - & - & - \\
PB (range: 6-20) & 12.48 & 2.71 & 0.02 & 0.15 & $0.23 * *$ & -0.15 & -0.13 & $-0.22 * *$ & $-0.19 *$ & -0.10 & -0.10 & - & - & - & - & - \\
A1 (range: 0-48) & 32.97 & 8.39 & 0.09 & -0.10 & -0.10 & 0.12 & 0.07 & 0.12 & $0.16^{*}$ & 0.12 & 0.13 & -0.14 & - & - & - & - \\
A2 (range: 12-48) & 21.06 & 9.74 & 0.04 & 0.07 & 0.07 & -0.03 & -0.03 & 0.02 & 0.01 & -0.12 & -0.10 & -0.06 & $0.28^{*}$ & - & - & - \\
B1 (range: 0-36) & 22.48 & 8.45 & 0.14 & -0.10 & $0.24 * *$ & 0.03 & -0.03 & 0.03 & 0.08 & 0.04 & 0.09 & -0.09 & $0.69 * *$ & $0.25 *$ & - & - \\
B2 (range: 9-36) & 17.30 & 6.27 & 0.12 & 0.15 & $0.27 * *$ & -0.04 & -0.07 & 0.01 & -0.04 & -0.11 & -0.07 & -0.03 & $0.22 *$ & $0.73 * *$ & $0.31 *$ & - \\
Parent's sex (female = 1) & - & - & 0.02 & -0.13 & -0.01 & $0.23 * *$ & $0.16 *$ & $0.22 * *$ & $0.21 * *$ & $0.20^{*}$ & $0.17 *$ & $-0.24 *$ & $0.52 * *$ & $0.30^{*}$ & $0.37 *$ & $.32 *$ \\
\hline
\end{tabular}

$* \mathrm{p}<0.05, * * \mathrm{p}<0.01$

FS, functional status of the child with disability; WFC, work-family conflict; FWC, family-work conflict; WFE-D, workfamily enrichment: development; WFE-A - Work-family enrichment: affect; WFE-C - Work-family enrichment: capital; FEW-D - Family-work enrichment: development; FEW- A - Family-work enrichment: affect; FEW-C- Family-work enrichment: capital; PB - Parents' beliefs about gender roles; A1 - Responsibilities towards a child with a disability - scope of undertaken responsibilities; A2 - Responsibilities towards a child with a disability - sense of burden; B1 - Household and family responsibilities - scope of undertaken responsibilities; B2 - Household and family responsibilities - sense of burden

with family-work conflict and selected aspects of work-family and family-work enrichment.

Table 2. Multivariate relationship between the parent's sex, functional status of the child, parent's beliefs about gender roles and responsibilities - scope of undertaken responsibilities, sense of burden, and work-family/family-work conflict. Multiple linear regressions analysis ( $\beta$, Standardized regression coefficient)

\begin{tabular}{|l|c|c|}
\hline Variable & $\begin{array}{c}\text { Work-family } \\
\text { conflict }\end{array}$ & $\begin{array}{c}\text { Family-work } \\
\text { conflict }\end{array}$ \\
\hline Parent's sex & -0.08 & 0.03 \\
FS & 0.06 & $-0.19^{*}$ \\
PB & 0.14 & $0.24^{* *}$ \\
A1 & 0.07 & -0.05 \\
A2 & 0.05 & 0.00 \\
B1 & -0.1 & -0.12 \\
B2 & 0.15 & $0.34^{* *}$ \\
\hline
\end{tabular}

$* \mathrm{p}<0.05, * * \mathrm{p}<0.01$

FS - Functional status of the child with disability; WFCWork - family conflict; FWC-Family - work conflict; PB - Parents' beliefs about gender roles; A1 - Responsibilities towards a child with a disability - scope of undertaken responsibilities; A2 - Responsibilities towards a child with a disability - sense of burden; B1 - Household and family responsibilities - scope of undertaken responsibilities; B2 Household and family responsibilities - sense of burden
Using the regression model, we assessed the contribution of covariates and predictors to categorising the intensity of the results of the conflict in both directions: work-family and family-work. Gender was found to be insignificant. The model created for the variable work-family conflict was statistically insignificant $(F(7.13)=1.22, p=$ $\left.0.296, \Delta R^{2}=0.06, R^{2}=0.01\right)$. In the case of the family-work conflict model, the values of predictors such as beliefs about gender roles and the feeling of being burdened with household and family responsibilities were significant $(F(7.13)=4.51$, $\left.p<0.001, \Delta R^{2}=0.19, R^{2}=0.15\right)$. Moreover, the covariate of the functional status of a child with a disability was significant as well. As a result, more intense family-work conflict was associated with a greater subjectively perceived burden of household and family responsibilities, while stronger beliefs were associated with a traditional division of roles according to gender, and a lower functional status of the child indicated that the child lacked independence in their life and had diminished abilities.

The established coefficients informing about the range of the explained variance of the criterion variable and the strength of the relationship with predictors and covariates were usually weak. In 
the model explaining family-work conflict, which turned out to be significant, the variables explained $15 \%$ of the variance of the corresponding to conflict increase as a criterion variable. Furthermore, the strongest relationship observed was the predictor of the burden of household and family responsibilities ( $\beta=0.34, p=0.001)$, while the weaker relationship was that of beliefs about gender roles $(B=0.24, p$ $=0.003)$, and the weakest for the functional status of a child with a disability $(\beta=-0.19, p=0.017)$.

In the regression model, aspects of work-family and family-work enrichment were included in sequence: development, affect, and capital. All models, apart from the model explaining the results of the work-family affect variable, turned out to be significant. In almost all models, apart from the work-family affect, the parent's sex was important. For work-family development, the regression model fitted the data well $(F(7.13)=$ $\left.2.13, p=0.046, \Delta R^{2}=0.1, R^{2}=0.05\right)$. The variables analysed here, of which only the parent's sex turned out to be significant ( $\beta=0.27, p=0.008$ ), explain only $5 \%$ of the increase in the variance of the criterion variable. Data showed that women experienced stronger work-to-family development than men. The model created for the work-family affect variable $\left(F(7.13)=1.79, p=0.095, \Delta R^{2}=\right.$ $\left.0.09, R^{2}=0.04\right)$ had even weaker predictive power because it explained only $4 \%$ of the increase in the variance of the criterion variable. It also turned out to be statistically insignificant. The parent's sex $(\beta=0.24, p=0.017)$ and beliefs about gender roles $(\beta=-0.19, p=0.026)$ were significant for determining the results of the work-family capital variable. The model obtained here was significant $\left(F(7.14)=2.45, p=0.022, \Delta R^{2}=0.11, R^{2}=0.07\right)$, but explained only a small part of the increase in the criterion variable. Women, and individuals with egalitarian beliefs about gender roles were found to experience a greater gain in capital for their family life through participation in professional roles than men and individuals with traditional beliefs.

Considering family-work development, the regression model fitted the data well $(F(7.13)=$ $\left.2.28, p=0.032, \Delta R^{2}=0.11, R^{2}=0.06\right)$. However, it had relatively little power to explain the increase in the variance of the criterion variable. In this case, apart from the parent's $\operatorname{sex}(\beta=0.2, p=0.045)$, beliefs regarding gender roles turned out to be significant $(\beta=-0.17, p=0.041)$. It can, therefore, be inferred that women and people with stronger egalitarian beliefs experience greater family-work development. In the model explaining the family-work affect variable $(F(7.13)=2.36, p=0.026$, $\left.\Delta R^{2}=0.11, R^{2}=0.06\right)$, gender $(\beta=26, p=0.012)$ and fulfilling household and family responsibilities ( $\beta=25, p=0.034)$ had significant positive relationships with the criterion variable. Compared to men, women and people who took greater responsibility for household and family duties experi-

Table 3. Multivariate relationship between parent's sex, functional status of the child, parent's beliefs about gender roles and responsibilities - scope of undertaken responsibilities, sense of burden, and work-family/family-work enrichment. Multiple linear regressions analysis ( $\beta$, Standardized regression coefficient)

\begin{tabular}{|l|c|c|c|c|c|c|}
\hline Variable & WFE-D & WFE-A & WFE-C & FWE-D & FWE-A & FWE-C \\
\hline Parent's sex & $0.27^{* *}$ & 0.20 & $0.24^{*}$ & $0.20^{*}$ & $0.26^{*}$ & $0.21^{*}$ \\
FS & -0.11 & $-0.17^{*}$ & -0.13 & -0.07 & -0.05 & -0.00 \\
PB & -0.09 & -0.11 & $-0.19^{*}$ & $-0.17^{*}$ & -0.06 & -0.08 \\
A1 & -0.18 & -0.16 & -0.17 & -0.15 & -0.18 & -0.14 \\
A2 & -0.12 & -0.08 & -0.03 & -0.02 & -0.10 & $-0.25^{*}$ \\
B1 & 0.18 & 0.11 & 0.14 & 0.22 & $0.25^{*}$ & $0.23^{*}$ \\
B2 & -0.05 & -0.06 & -0.04 & -0.12 & -0.16 & -0.00 \\
\hline \multicolumn{7}{|r|}{$\mathrm{N}=141$} \\
\hline
\end{tabular}

${ }^{*} \mathrm{p}<0.05, * * \mathrm{p}<0.01$

FS - Functional status of the child with disability; WFE-D - Work-family enrichment: development; WFE-A - Work-family enrichment: affect; WFE-C - Work-family enrichment: capital; FEW-D - Family-work enrichment: development; FEW- A - Family-work enrichment: affect; FEW-C- Family-work enrichment: capital; PB - Parents' beliefs about gender roles; A1 Responsibilities towards a child with a disability - scope of undertaken responsibilities; A2 - Responsibilities towards a child with a disability - sense of burden; B1 - Household and family responsibilities - scope of undertaken responsibilities; B2 Household and family responsibilities - sense of burden 
enced a stronger family-work affective enrichment. However, the power to explain the increase in the variance of the family-work affect variable was weak (only $6 \%$ ). In the case of the last criterion variable, family-work capital, the regression model fitted the data well $\left(F(7.13)=2.43, p=0.022, \Delta R^{2}\right.$ $\left.=0.11, R^{2}=0.07\right)$ although it had weak predictive power. Three variables: parent's sex $(\beta=21, p=$ $0.035)$, feeling burdened with the responsibilities related to raising a child with a disability $(\beta=-25$, $p=0.043)$, and responsibility for household and family duties $(\beta=23, p=0.047)$ had significant relationships with the criterion variable in different directions. To conclude, women and people who feel less burdened with the responsibilities of caring for a child with a disability and those who take greater responsibility for domestic and family duties were found to experience greater enrichment in the capital accumulated in the family and transferred to the work domain.

\section{DISCUSSION}

This study investigated the contribution of parental beliefs and the scope of responsibility born in connection with family obligations towards a child with a disability, as well as domestic and family matters and the sense of burden with duties to shaping the results of role conflict and enrichment in two directions: family-to-work and work-to-family. Additionally, the parent's sex and the functional status of the child with a disability (reflecting the child's abilities in terms of basic self-service activities and mobility) were considered. The results of the analyses indicate that none of the tested variables formed significant associations with the work-family conflict variable in the tested model. In the case of family-work conflict, the burden of household chores, traditional beliefs about gender roles, and a lower level of life independence and efficiency of the child with a disability were found to be significant. Variables that were not significant in the model included: parent's sex, caregiving and upbringing of the child, fulfilling household duties, and the burden of household duties. The lack of a significant contribution of the gender variable for both types of conflict is consistent with the results obtained by other authors (Haines et al., 2019; Mortazavi et al., 2009, in Jaga \& Bagraim,
2017; Smith, Yu \& Le, 2020). The fact that gender role beliefs proved significant in the case of family-work conflict may support the assumption made by Huffman et al. (2014) of the greater analytical utility of the latter variable, and not of gender itself.

The nature of the contribution of traditional beliefs is consistent with the findings of other researchers (Kuo et al., 2018; Nomaguchi, 2009; Steiner et al., 2019). Our results align with expectations, however, in order for them to be consistent, one would expect a significant role of the burden of responsibilities related to the upbringing of a child with a disability, which was related to the child's greater needs resulting from a lower level of life independence. What is important for interpreting the established trend is the fact that both parents in the study group reported working professionally. Mothers who have taken up professional work creates a divergence from the traditional view of family roles (Duxbury \& Higgins, 1991; Kaufman \& White, 2016; Lewis, 2000, in Leiter et al., 2004; Steiner et al., 2019). Perhaps it causes a stronger feeling of being burdened with household duties. It can also potentially be a factor evoking negative emotions, feelings, and assessments related to time limitations due to work, which can or should be devoted to the child with a disability, especially if the child's independence is low, as indicated by the relationship with the variable of the functional status (Steiner et al., 2019). On the other hand, the suggested time constraints could potentially provoke a work-family conflict (Steiner et al., 2019), which was not observed in the current analysis - significant relationships were noted in the area of the other conflict.

In contrast to role conflict, in the case of enrichment in both directions, the gender variable was found to be significant in almost every model. In every case, women experienced greater enrichment, accompanied in some aspects by stronger egalitarian beliefs. Both variables were important for family-work development and work-family capital. It was found that stronger work-family development and capital enrichment can have an effect on women, while the latter has an effect on people with stronger egalitarian beliefs as well. Women, unlike men, with more egalitarian beliefs about gender roles, experienced stronger family-work development. Women and individuals who fulfiled 
domestic and family responsibilities to a greater extent experienced greater affect and enrichment in capital transferred from the family to work. In the latter case, this also applied to people who feel less burdened with the responsibilities related to raising a child with a disability. Our results are consistent with the findings of other authors who show a significant contribution of the gender variable in the case of enrichment (Beham et al., 2020; Rothbard, 2001; Van Steenbergen, 2007).

Taking up family and professional roles can be a source of enrichment for women in many dimensions and in both directions, especially if they have egalitarian views (Beham et al., 2020). The present study showed that family becomes a domain for developing and strengthening positive states resulting from satisfying psychosocial needs, such as a sense of fulfilment, achievement, and success (capital). It allows the individual to develop positive emotions, feelings, and attitudes, which in turn can be an element of shaping self-image, strengthening identity, and increasing self-efficacy or optimism (Greenhaus \& Powell, 2006). These competencies are important for taking on the challenges related to roles, in this case, home and family responsibilities. Fulfilment of family roles and the resulting obligations, in this case, related to home and family (analysed here at the level of responsibilities undertaken just like work) is a source of competencies and positive states (including positive emotions and affects) essential for taking up professional duties. The experience of gaining capital in the form of the aforementioned sense of fulfilment, achievements, and successes in the family and their positive use at work increase with a decrease in the intensity of the burden of taking care of a child with a disability among women taking more responsibility for home and the family. Mothers of children with disabilities were more likely to fulfil domestic, caring, and educational obligations than fathers, which is consistent with previous studies (Fernandes-Cornejo et al., 2016; Haines et al., 2018; Kaplan et al., 2020). Moreover, they felt a greater burden associated with it. They also presented an egalitarian attitude more often. Researchers report that broadly understood non-traditional attitudes related to gender roles (including gender identity) may be associated with higher self-esteem, autonomy, and coping skills
(Kleinplatz et al., 1992). Hatchman (2009) suggested that the women with non-traditional gender role attitudes may be well prepared to cope with the stress of managing work and family roles. Taking up broadly understood family responsibilities plays an important role in strengthening maternal and feminine identities (Kaplan et al., 2020), which in turn makes this area of life an important source of resources (cf. Beham et al., 2020). Referring to previously described trends regarding conflict, it can be concluded that mothers who take on a larger proportion of family responsibilities, but also feel more burdened with them, do not experience a greater conflict than fathers of children with disabilities. This could potentially explain their ability to balance family and professional lives, or even to notice specific benefits resulting from functioning in both areas.

Parental involvement in domestic and family responsibilities or those related to raising a child with a disability may increase a parent's sense of burden, but on the other hand, it is a potential source of satisfaction and enhancement of competencies. Meteyer and Perry-Jenkins (2010) cited studies showing that working women feel more competent in the maternal role when they are the main caregiver for the child. Other analyses show that the perceived degree of responsibility in women for the financial support of the family, associated with the belief that they have a significant share in the family budget, is one of the elements conducive to the implementation of professional and family roles (Helms-Erikson et al., 2000). Perhaps in this case, especially in mothers, the perceived responsibility for family matters has a positive influence on seeing one's own significant role in it, including strengthening competencies or even satisfaction, which is conducive to noticing enrichment. Although this was not analysed in the present study, many studies highlight the special potential of mothers of children with disabilities who take on many non-standard roles (the role of a therapist, teacher, advocate of the child's interests, support group leader) to perform these roles on their own without much partner's involvement (Van Riper, 2007).

The presented study is cross-sectional, and it captures a certain fragment of the reality where parents of children with disabilities function, but it 
does not trace the dynamics of changes, and cannot be used to make conclusions about causal relations. Children with disabilities were of different ages, which is important for the nature of the caregiving required and the educational responsibilities. The functional status was subjectively assessed by the parents and included as a general indicator of the child's independence. The way of interpreting parental beliefs may be seen as a simplification, although it is practiced in the literature on the subject. Additionally, analyses involving individuals with high levels of traditional or egalitarian beliefs would be of great importance, but this requires a larger sample. Future studies involving parents of children with disabilities should involve dyad analyses to study the importance of beliefs and the perceived division of responsibilities in pairs of partners or parents. It is worth exploring the diverse experiences in the population of parents of children with disabilities, including those who show continuity of employment or return to work after a break.

This study is important, first of all, since we need to rationally support parents in the context of specific socio-cultural and economic conditions. This is especially important for mothers so that they can fulfil their needs and motives related to work successfully, and at the same time not experience concerns about providing their child with a disability with care appropriate to the child's needs. This applies to children of all ages because, in contrast to non-disabled children, this population is more likely to need lifelong support and care (Alnazly \& Abojedi, 2019; Leiter et al., 2004).

Based on the trends observed here, it seems that access to support, at the organisational and institutional level, is important for positive experiences in reconciling family and work roles (their enrichment) for parents of children with disabilities. Work arrangements that make up the so-called family-friendly environment may play a key role here (McNall et al., 2010; Siu et al., 2010). These include workplace organisational policies (the rule of flexible time and place), services (referring to specific resources, for example, information resources such as training, counseling), and benefits (including specific solutions, for example, childcare for children under the compulsory school age). On the other hand, it is important to support parents in meeting family and domestic responsibilities, including those related to raising a child with a disability. It will be important not only to provide care, but above all its adequacy to the needs of a given family, in addition to instrumental, financial, or psychological support provided according to their needs. This support is important to activate and strengthen the parents' potential. Such support can be provided by educational, social, or medical institutions and has the potential to reduce parental stress and feelings of the burden of responsibilities, which are related to conflict. As far as psychological support is concerned, counselling for spouses/partners should be considered, aimed at raising awareness of the partners' needs, including those related to self-realisation (e.g., in professional work), but also concerning participation in household and family duties (a division of responsibilities). This may be one way of reinforcing/developing beliefs of accepting gender equality in access to roles and tasks, even though they are largely formed through socialisation (Fortin, 2005). 


\section{REFERENCES}

Alborz, A. (2003). Transitions: placing a son or daughter with intellectual disability and challenging behaviour in alternative residential provision. Journal of Applied Research in Intellectual Disabilities, 16,75-88.

Alnazly, E. K., \& Abojedi, A. (2019). Psychological distress and perceived burden in caregivers of persons with autism spectrum disorder. Perspectives in Psychiatric Care, 55, 501-508.

Aryee, S., Srinivas, E., \& Tan, H. (2005). Rhythms of life: antecedents and outcomes of work-family balance in employed parents. Journal of Applied Psychology, 90, 132-146.

Bansal, N., \& Agarwal, U. A. (2019). Direct and indirect effects of work? Family enrichment: role of gender role ideology. International Journal of Productivity and Performance Management, 69, 873-894.

Beham, B., Drobnič, S., Präg, P., Baierl, A., \& Lewis, S. (2020). Work-to-family enrichment and gender inequalities in eight European countries. The International Journal of Human Resource Management, 31, 589-610.

Bicaksiz, P. (2009). The effects of gender role ideology, role salience, role demands and core self-evaluations on work-family interface (Master's thesis). Graduate School of Social Sciences of Middle East Technical University. Retrieved from https://etd.lib.metu.edu.tr/upload/12610950/index.pdf

Boyd, M. J., Iacono, T., \& McDonald, R. (2019). The perceptions of fathers about parenting a child with developmental disability: a scoping review. Journal of Policy and Practice in Intellectual Disabilities, 16, 312-324.

Brennan, E. M., \& Brannan, A. M. (2005). Participation in the paid labor force by caregivers of children with emotional and behavioral disorders. Journal of Emotional and Behavioral Disorders, 13, 237-246.

Brown T. J., \& Sumner, K. E. (2019). Cross national examination of work family in parents of children with disabilities using a bioecological model. Child \& Youth Care Forum, 48, 703-718.

Brown, T. J. (2014). Work family conflict among parents of atypically developing children: exploring the impact of worker, work, and child factors. Journal of Child and Family Studies, 23, 854-862.

Brummelhuis, L., van der Lippe, T., Kluwer, E., \& Flap, H. (2008). Positive and negative effects of family involvement on work-related burnout. Journal of Vocational Behavior, 73, 387-396.

Brummelhuis, L., van der Lippe, T., Kluwer, E., \& Flap, H. (2008). Positive and negative effects of family involvement on work-related burnout. Journal of Vocational Behavior, 73, 387-396.

Butler, A. B., \& Skattebo, A. (2004). What is acceptable for women may not be for men: The effect of family conflicts with work on job-performance ratings. Journal of Occupational and Organizational Psychology, 77, 553-564.

Carlson, D., Kacmar, K., Wayne, J., \& Grzywacz, J. (2006). Measuring the positive side of work-family interface: development and validation of a work-family enrichment scale. Journal of Vocational Behavior, 68, 131-164.

Chou, Y-C., Kroger, T., \& Pu, C. Y. (2016). Universal breadwinner versus universal caregiver model: fathers' involvement in caregiving and well-being of mothers of offspring with intellectual disabilities. Journal of Applied Research in Intellectual Disabilities, 29, 34-45.

Churchill, S. S., Villareale, N. L., Monaghan, T. A., Sharp, V. L., \& Kieckhefer, G. M. (2010). Parents of children with special health care needs who have better coping skills have fewer depressive symptoms. Maternal and Child Health Journal, 14, 47-57.

Claffey, S. T., \& Mickelson, K. M. (2009). Division of household labor and distress: the role of perceived fairness for employed mothers. Sex Roles, 60, 819-831.

Cooper, S. M., Ross, L., Dues, A., Golden, A. R., \& Burnett, M. (2019). Intergenerational factors, fatherhood beliefs, and african american fathers' involvement: building the case for a mediated pathway. Journal of Family Issues, 40, 2047-2075.

Crettenden, A., Wright, A., \& Skinner, N. (2014). Mothers caring for children and young people with developmental disabilities: intent to work, patterns of participation in paid employment and the experience of workplace flexibility. Community, Work and Family, 17, 244-267. 
Cunningham, M. (2008). Influences of gender ideology and housework allocation on women's employment over the life course. Social Science Research, 37, 254-267.

Davies, S. N., \& Greenstein, T. N. (2009). Gender ideology: components, predictors, and consequences. Annual Review of Sociology, 35, 87-105.

Davys, D., \& Haigh, C. (2007). Older parents of people who have a learning disability: perceptions of future accommodation needs. British Journal of Learning Disabilities, 36, 66-72.

DePasquale, N., Polenick, C., Davis, K.D., Moen, P., Hammer, L.B., \& Almeida, D.M. (2017). The psychosocial implications of managing work and family caregiving roles: Gender differences among information technology professionals. Journal of Family Issues, 38, 1495-1519.

Dodson, T. A., \& Borders, L. DA. (2006). Men in traditional and nontraditional careers: gender role attitudes, gender role conflict, and job satisfaction. The Career Development Quarterly, 54, 283-296.

Duxbury, L.E., \& Higgins, C.A.(1991). Gender differences in work-family conflict. Journal of Applied Psychology, $76,60-74$.

Einam, M., \& Cuskelly, M. (2002). Paid employment of mothers and fathers of an adult child with multiple disabilities. Journal of Intellectual Disability Research, 46, 158-167.

Favez, N., Tissota, H., Frascarolob, F., Stiefelb, F., \& Despland, J. N. (2016). Sense of competence and beliefs about parental roles in mothers and fathers as predictors of coparenting and child engagement in mother-father-infant triadic interactions. Infant and Child Development, 25, 283-301.

Feinberg, M. E. (2003). The internal structure and ecological context of coparenting: a framework for research and intervention. Parenting: Science and Practice, 3, 95-131.

Fernandes-Cornejo, J., Escot, L., Kabubo-Mariara, J., Kinuthia, B. K., Eydal, G. B., \& Bjarnson, T. (2016). Gender differences in young adults' inclination to sacrifice career opportunities in the future for family reasons. A comparative study with university students from Nairobi, Madrid and Reykjavik. Journal of Youth Studies, 19, 457-482.

Fortin, N. M. (2005). Gender role attitudes and the labour-market outcomes of women across OECD countries. Oxford Review of Economic Policy, 21, 416-438.

Gartrell Hatchman, B. (2009). Women's gender role attitudes, career salience, and paid work-family conflict (Doctoral dissertation. Auburn University).Retrieved from

http://etd.auburn.edu/xmlui/bitstream/handle/10415/2027/B.Hatchman\%20Dissertation.pdf?sequence=1\&isAllowed=y

Gaunt, R. (2006). Biological essentialism, gender ideologies, and role attitudes: what determines parents' involvement in child care. Sex Roles, 55, 523-533.

Gelb, J. (2014). Role centrality, gender role ideology and work-family conflict among working fathers in South Africa (Master's thesis). University of Cape Town. Retrieved from https://open.uct.ac.za/bitstream/handle/11427/13686/ thesis_hum_2015_gelb_ja.pdf?isAllowed=y\&sequence $=1$

Gray, D. E. (2003). Gender and coping: the parents of children with high functioning autism. Social Science and Medicine, 56, 631-642.

Greenhaus, J. H., \& Powell, G. N. (2006). When work and family are allies: a Theory of work-family enrichment. Academy of Management Review, 31, 72-92.

Greenhaus, J. H., \& Beutell, N. J. (1985). Sources of conflict between work and family role. Academy of Management Review, 10, 76-88.

Grzywacz, J., Butler, A., \& Almeida, D. (2008). Work, family, and health: work-family balance as a protective factor against stresses of daily life. In A. Marcus-Newhall, D. Halpern, S. Tan (Eds.), The changing realities of work and family. A multidisciplinary approach (pp. 194-215). Wiley-Blackwell. 
Haines, V. Y., Bilodeau, J., Demers, A., Marchand, A., Beauregard, N., Durand, P., \& Blanc, M-E. (2019). Sex, gender dynamics, differential exposure, and work-family conflict. Journal of Family Issues, 40, 215-239.

Harris, R. J., \& Fireston, J. M. (1998). Changes in predictors of gender role ideologies among women: a multivariate analysis. Sex Roles, 38, 239-252.

Hauge, L. J., Kornstad, T., Nes, R. B., Krisensen, P., Irgnes, L.M., Eskedal, L. T., Landolt, M. A.,\& Vollarath, M. E. (2013). The impact of a child's special health care needs on maternal work participation during early motherhood. Paediatric and Perinatal Epidemiology, 27, 353-360.

Helms-Erikson, H., Tanner, J. L., Crouter, A. C., \& McHale, S. M. (2000). Do women's provider role attitudes moderate the links between work and family? Journal of Family Psychology, 14, 658-670.

Hergatt Huffman, A., Olson, K. J., O’Gara, T. C., \& King, E. B. (2014).Gender role beliefs and fathers' work-family conflict. Journal of Managerial Psychology, 29, $774-793$.

Jaga, A., \& Bagraim, J. (2011). The relationship between work-family enrichment and work-family satisfaction outcomes. South African Journal of Psychology 41, 52-62.

Jaga, A., \& Bagraim, J. (2017). Work-family conflict among Hindu mothers in South Africa. International Journal of Manpower, 38, 1086-1101.

Jugović, I. (2015). Beliefs about the gender division of parental leave and characteristics associated with them. Revija za Socijalnu Politiku, 23, 359-382.

Kaplan, A., Sabbah-Karkabi, M., \& Herzog, H. (2020). "When I iron my son's shirt, I feel my maternal role": making women's invisible work visible. Journal of Family Issues, 41, 1525-1545.

Kaufman, G., \& Uhlenberg, P. (2000). The influence of parenthood on the work effort of married men and women. Social Forces, 78, 931-947.

Kaufman, G., \& White, D. (2016). "For the good of our family": men's attitudes toward their wives' employment. Journal of Family Issues, 37, 1585-1610.

Kleinplatz, P., McCarrey, M., \& Kateb, C. (1992). The impact of gender-role identity on women's self-esteem, lifestyle satisfaction and conflict. Canadian Journal of Behavioural Science, 24, 333-347.

Kroska, A., \& Elman, C. (2009). Change in attitudes about employed mothers: Exposure, interests, and gender ideology discrepancies. Social Science Research, 38, 366-382.

Kuo, P. X., Volling, B. L., \& Gonzalez, R. (2018). Gender role beliefs, work-family conflict, and father involvement after the birth of a second child. Psychology of Men \& Masculinity, 19, 243-256.

Leiter, V., Wyngaarden Krauss, M., Anderson, B., \& Wells, N. (2004). The consequences of caring. Effects of mothering a child with special needs. Journal of Family Issues, 25, 379-403.

MacDonald, E. E., \& Hastings, R. P. (2010). Mindful parenting and care involvement of fathers of children with intellectual disabilities. Journal of Child and Family Studies, 19, 236-240.

Marks, J., Bun, L. C., \& McHale, S. M. (2009). Family patterns of gender role attitudes. Sex Roles, 61 (3-4), $221-234$.

Matthews, R., Kath, L.,\& Barnes-Farrell, J. (2010). A short, valid, predictive measure of work-family conflict: item selection and scale validation. Journal of Occupational Health Psychology, 15, 75-90.

Mavrogianni, T., \& Lampropoulou, V. (2020). The involvement of fathers with their deaf children, international journal of disability. Development and Education, 67, 45-57.

McNall, L., Masuda, A.,\& Nickin J. (2010). Flexible work arrangements, job satisfaction, and turnover intentions: the mediating role of work-to-family enrichment. The Journal of Psychology, 144, 61-81.

Mencarni, L., \& Vignoli, D. (2018). Employed women and marital union stability: it helps when men help. Journal of Family Issues, 39, 1348-1373. 
Meteyer, K., \& Perry-Jenkins, M. (2010). Father involvement among working-class, dual-earner couples. Fathering: A Journal of Theory, Research, and Practice about Men as Fathers, 8, 379-403.

Nomaguchi, K. M. (2009). Change in work-family conflict among employed parents between 1977 and 1997. Journal of Marriage and Family, 71, 15-32.

Olrick, J. T., Pianta, R. C., \& Marvin, R. S. (2002). Mother's and father's responses to signals of children with cerebral palsy during feeding. Journal of Developmental and Physical Disabilities, 14, 3-17.

Öun, I. (2012). Work-family conflict in the Nordic countries: a comparative analysis. Journal of Comparative Family Studies, 43, 165-184.

Ozgun, O. A., \& Sterling Honig, A. (2005). Parental involvement and spousal satisfaction with division of early childcare in Turkish families with normal children and children with special needs. Early Child Development and Care, 175, 259-270.

Pancsofar, N., Petroff1, J. G., Rao, S., \& Mangel, A. (2020). "What I want to do as a father is be there": constructions of school involvement for fathers of children with complex disabilities. Research and Practice for Persons with Severe Disabilities, 44, 153- 168.

Perälä-Littunen, S. (2007). Gender equality or primacy of the mother? Ambivalent descriptions of good parents. Journal of Marriage and Family, 69, 341-351.

Perälä-Littunen, S. (2018). Childcare and work-exploring the views of Finnish mothers and fathers. Community, Work \& Family, 21, 209-225.

Perales, F., Jarallah, Y., \& Baxter, J. (2018). Men's and women's gender-role attitudes across the transition to paretnthood: accouting for child's gender. Social Forces, 97 (1), 251-276.

Perry-Jenkins, M., Herman, R. J., Halpern, H. P., \& Newkirk, K. (2017). From discovery to practice: translating and transforming work-family research for the health of families. Family Relations, 66, 614-628.

Potter, C. A. (2017). Father involvement in the care, play, and education of children with autism. Journal of Intellectual \& Developmental Disability, 42, 375-384.

Rajadhyaksha, U., Korabik, K., \& Aycan, Z. (2015) Gender, gender-role ideology, and the work-family interface: a cross-cultural analysis. In: M. Mills (ed.), Gender and the work-family experience. Cham: Springer.

Riina, E. M., \& Feinberg, M. E. (2012). Involvement in childrearing and mothers' and fathers' adjustment. Family Relations, 61, 836-850.

Rothbard, N. P. (2001). Enriching or depleting? The dynamics of engagement in work and family roles. Administrative Science Quarterly, 46, 655-684.

Rupp, K., \& Ressler, S. (2009). Family caregiving and employment among parents of children with disabilities on SSI. Journal of Vocational Rehabilitation, 30, 153-175.

Ryan, S., \& Runswick-Cole, K. (2008). Repositioning mothers: mothers, disabled children and disability studies. Disability \& Society, 23, 199-210.

Schippers, A., Berkelaar, M., Bakker, M., \& Van Hove, G. (2020). The experiences of Dutch fathers on fathering children with disabilities: 'Hey, that is a father and his daughter, that is it'. Journal of Intellectual Disability Research, 64, 442-454.

Sheran, J., \&Todd, S. (2000). Maternal employment and family responsibilities: the perspectives of children with intellectual disabilities. Journal of Applied Research in Intellectual Disabilities, 13, 109-131.

Šimunić, A., Pandža, M., \& Gregov, L. (2017). Some determinants of the perception of work-family conflict: a dyadic approach. Primenjena Psihologija, 10, 245-262. 
Sitimin, S. A., Fikry, A., Ismali, Z., \& Hussein, N. (2017). Work-family conflict among working parents of children with autism in Malaysia. Procedia Computer Science, 105, 345-352.

Siu, O., Lu J., Brough, P., Lu, C., Bakker, A. B., Kalliath, T. et al. (2010). Role resources and work-family enrichment: the role of work engagement. Journal of Vocational Behavior, 77, 470-480.

Smith, T. D. Yu, Z., \& Le, A. B. (2020). An examination of work interference with family using data from a representative sample of workers participating in the general social survey and NIOSH quality of worklife module. Journal of Family Issues, 41, 2356-2376.

Somech, A., \& Drach-Zahavy, A. (2007). Strategies for coping with work-family conflict: the distinctive relationships of gender role ideology. Journal of Occupational Health Psychology, 12, 1-19.

Steiber, N. (2009). Reported levels of time-based and strain-based conflict between work and family roles in Europe: a multilevel approach. Social Indicators Research, 93, 469-488.

Steiner, R. S., Krings, F., \& Wiese, B. S. (2019). Remember the children, honey! spouses' gender-role attitudes and working mothers' work-to-family conflict. Applied Psychology: an International Review, 201, 250-275.

Taber, K. S. (2018). The use of Cronbach's Alpha when developing and reporting research instruments in science education. Research in Science Education, 48, 1273-1296.

Taylor, N. E., Wall, S. M., Liebow, H., Sabatino, C. A., Timberlake, E. M.,\& Farber, M. Z. (2005). Mother and solider: raising a child with a disability in a low-income military family. Exceptional Children, 72, 83-99.

Van Riper, M. (2007). Families of children with Down syndrome: responding to "a change in plans" with resilience. Journal of Pediatric Nursing, 22, 116-127.

Van Steenbergen, E. (2007). Work-family facilitation: a positive psychological perspective on role combination (Doctoral dissertation, Leiden University). Retrieved from https:/openaccess.leidenuniv.nl/bitstream/handle/1887/12466/ Thesis.pdf? sequence $=16$

Voydanoff, P. (2004). Implications of work and community resources and demands for marital quality. Journal of Organizational Psychology, 9, 275-285.

Voydanoff, P. (2005). Consequences of boundary-spanning demands and resources for work-to-family conflict and perceived stress. Journal of Occupational Health Psychology, 10, 491-503.

Walls, J. K., Helms, H. M., \& Grzywacz, J. G. (2016). Intensive mothering beliefs among full-time employed mothers of infants. Journal of Family Issues, 37, 245-269.

Wayne, J. H., Grzywacz, J. G., Carlson D. S., \& Kacmar M. K. (2007). Work-family facilitation: A theoretical explanation and model of primary antecedents and consequences. Human Resource Management Review, 17, 63-76.

Wayne, J.H., Matthews, R., Crawford, W., \& Casper, W.J. (2019). Predictors and processes of satisfaction with workfamily balance: examining the role of personal, work, and family resources and conflict and enrichment. Human Resource Management Journal, 59,25-42.

Webber, G., \& Williams, C. (2008). Part-time work and the gender division of labour. Qualitative Sociology, 31, 15-36.

Wright, A., Crettenden, A., \& Skinner, N. (2016). Dads care too! Participation in paid employment and experiences of workplace flexibility for Australian fathers caring for children and young adult with disabilities. Community, Work \& Family, 19, 340-361.

Young, M. (2019). Does work-family conflict vary according to community resources? Family Relations, 68, 197-212.

Zvara, B. J., Schoppe-Sullivan, S. J. \& Kamp Dush, C. (2013). Fathers' involvement in child health care: associations with prenatal involvement, parents' beliefs, and maternal gatekeeping. Family Relations, 62, $649-661$. 